\title{
The Role of the Director of Educational Units and the Participation of the Teachers' Association in the Decision-making Process. An Overview of the Greek's Education System
}

\author{
Dr. Vasileios Platis \\ Department of Modern and Contemporary History, Aristotle University of Thessaloniki \\ E-mail: platisbasil@gmail.com \\ Msc. Athena Argyropoulou \\ Department of Business Administration, Alexander Technological Institution of \\ Thessaloniki \\ E-mail: athinaargyropoulou@yahoo.gr
}

Received: May 29, 2019 Accepted: June 25, 2019 Online published: July 17, 2019

doi:10.5296/jpag.v9i3.15110 ＵRL: https://doi.org/10.5296/jpag.v9i3.15110

\begin{abstract}
The present paper examines the concept of leadership, the types of leadership and especially the role that the Director plays regarding decision making in the Greek education system. It reviews the literature on the Greek case and through the negotiation and commentary of a specific example from the daily routine of the Greek school, demonstrates how important it is for the Director tooperate democratically and use the presence of the Teachers' Association for the benefit of the school.
\end{abstract}

Keywords: leadership, models of administration, director, teachers ' association, decision making

\section{Introduction}

The role of the Director of a school unit can be characterized as a focal and multi-level one. The Director of the school unit faces several challenges every day. He/she must manage effectively problems arising from the everyday life of the school, whose immediate solution ensures the proper functioning. 
At school, there are observed cases of circumvention of internal rules and behaviors that are within the bounds of illegality, by students. Additionally, the relations of teachers with each other and with the Director are not always desirable, so the Director on several occasions is forced to play the role of "peacemaker", balancing any conflicts.

At the same time, the Director is required to cooperate harmoniously with the parents' association and guardians to overcome any problems related to the school's infrastructure (e.g. poor state of the school building, inadequate heating) but also to address negative attitudes and students' misconducts.

From the above, it is understood that the Director of the school unit must be endowed with significant skills-talents, to be able to manage a wide range of challenges effectively. In recent years, problems in the school area have increased dramatically, which requires that teachers who undertake managerial positions be aware in advance of the difficulty and responsibility of the task they will perform.

The paper examines the interconnection between leadership models and the decision making process in Primary and Secondary Education in Greece. Especially studies the participation of the teachers' Association in case the leadership model favors this. That issue has preoccupied both Greek and global research, but not systematically. The reason for our involvement is that it concerns the daily functioning of the educational institutions, since the model of exercise of leadership and the degree of participation of teachers in the decision making is shaped to a significant extent the working climate.

The researchers used relevant bibliography and analyzed a case study. In order to draw to a secure conclusion, they used reports of twenty interviews in which teachers who work in the Secondary Education took place. The sample refers to active teachers, seven of whom held management positions during the survey period (February 2019). Thus, the case study was analyzed both from the point of view of the Director and the simple teacher. However, with regard to the management of this example, all participants have ruled against the authoritarian leadership of the Director, identifying our own views set out in the text.

\section{Leadership-Management Models}

In their attempt to identify the term "leadership", the researchers gave various definitions. The differentiation of the views expressed regarding the content of the term "leadership" is a consequence of its multidimensional nature as a social phenomenon, without underestimating and ignoring its importance for the proper functioning and in particular of the school unit (Andris 2015: 152).

According to Bourantas, "as leadership could be defined as the process of influencing thought, attitudes of a small or large, formal or informal group of people from one person (leader) in such a way that voluntarily and willingly with the appropriate cooperation give their best to effectively implement visions and goals stemming from the team's mission and ambition, for progress or a better future" (Bourantas 2017: 20-21).

Related definitions of the concept of "leadership" were given by Saitis (Saitis 2014: 115) and 
Katsaros (Katsaros 2008: 96). Saitis, even more, pointed out that the exercise of leadership does not depend on the hierarchical position of someone in an organization.

Instead, Andris included the leader's attributes as the coordinator and regulator of the group, whose initiatives aim to create a strong communicative bond between its members to effectively realize the goals set forth from the leader (Andris 2015: 152).

In general, the relative ambiguity that characterizes the definition of the term "leadership" is reflected in the imaginative characterization of W. Bennis, who states that "leadership is the most visible everyday phenomenon on earth that we have barely understood".He resembled the leadership with beauty, as, according to his opinion, the concepts of leadership and beauty are difficult to define, but both could be perceived as soon as someone copy with them (cited in Agapitou 2012: 37).

Regarding the types of leadership, the views presented in the literature could be divided into two groups. Bourantas distinguishes the following forms of exercise of leadership. In charismatic or transformative leadership that states that there is an emotional correlation between the two parties, while the Director, cultivating the appropriate communication profile, passes to his collaborators the messages he wants.

In terms of transformational leadership, the researcher encompasses the characteristics of ideological influence, inspirational motivation, intellectual activation and individualistic interest. Also, in exercising loose leadership, Bourantas points out the risk of disclaiming the role of the Director of the school unit that stems from the hierarchy, and relegation of his position and influence on the association of teachers.

The original leadership, moreover, in the "model" of Bourantas refers to the authenticity of the leader, as the leader possesses self-knowledge, morality and ambition, and is distinguished by sincerity, openness, transparency, principles, values, trust and self-sufficiency.

As ethical leadership, he considers the one that is harmonized with the rules and moral values, provided that the leader is law-abiding. Finally, the attributes of spiritual leadership, according to Bourantas, are altruism, humility and love (Bourantas 2017: 43-49).

On the contrary, Andris limits the types of leadership to the following three: (a) The authoritarian leadership, in which the bipolar enforcement of the director-leader towards his subordinates has an imposing-despotic character, which eliminates the meaningful communication between them, limited by hierarchical protocols, resulting in a loss of human character in cooperation that fits the nature of the profession (b) The loose leadership, where the director acts as an information transponder through collective decision-making. He does not distinguish his position, resulting from being exploited by his subordinates and (c) The democratic leadership, in the exercise of which multiple opinions are expressed, there is freedom of speech, meaning dialogue, and with the appropriate Coordination, supervision and control, the Director can achieve the best result, i.e. the proper utilization of human resources.

In the aforementioned distinction of power types, Andris prefers the Democratic "style" as the 
most effective and criticises the other two. In particular, he rejects authoritarian leadership, as it is likely that its exercise will lead to "depersonalization" and "standardisation" of relations between teachers. The director often invokes the institutional framework for exercising his authority; it is possible this to turn himself into a rigid bureaucrat, thereby weakening the coherence and creativity of the group of teachers (Andris 2015: 153-154).

Saitis, in his project "initiation of teachers in the secrets of the school leadership" distinguishes the following basic models of educational administration: the typical models, cooperative models, the transactional (or bargaining) and transformational leadership. The models of the first category (e.g. structural, bureaucratic, hierarchical) perceive the school as a hierarchical system in which the Director seeks to achieve predetermined objectives using reasonable means, his authority necessarily results from his official position in the hierarchy.

Unlike the models in the previous category, the cooperative models are based on the participation of teachers in decision making, which favors the behavior of the Director of the school unit. The latter promotes unanimity in decision making and in no case, tries to impose on the teachers of the school unit using his power.

In the trading or bargaining exercise of the leadership, according to the separation of the educational management models introduced by the Saitis, the intent is to make the transaction (give and take) between the director and his subordinates is required to carry out the tasks assigned by the Director to the teachers of the school and to receive reward for their services.

On the contrary, in the model of transformational leadership that the researcher seems to adopt towards all others, the leader strives to inspire teachers to join him in the vision he develops for the school unit, promotes co-operation and participation in decision-making, while he attempts to influence them to contribute to the realization of his vision.

Saitis emphasises that the implementation of the above-mentioned leadership models aims at forging real relationships between teachers in the school unit through interaction and is sharply differentiated by the formation of formal transactional relationships between the director and the teachers. A typical example of transformational leadership is, according to Saito, Martin Luther King, whose vision for overthrowing the black position was condensed into the common phrase "I have a Vision" (Saitis 2014: 121-123).

With regard to the various forms of school leadership, Saitis distinguishes authoritarian leadership, democratic-participatory leadership, loose leadership and bureaucratic leadership (Saitis 2014: 139-140).

Ioannis Katsaros, compared to Buranta's "scheme" previously discussed, adopted the transformational leadership as well as the moral leadership, which he defined in a similar way. Katsaros, apart from these two forms of leadership, also cited the administrative leadership, which he fully identified the concept of administration with that of leadership, the participatory leadership, which he makes with moral leadership and considers as a prerequisite for the exercise of Teamwork, as well as potential direction, where no type of leadership is regarded as the most appropriate and is chosen to use a "mixture" of theoretical approaches to leadership, in order to better achieve the leader's objectives (Katsaros 2008: 
106-112).

In particular, in the model of administrative leadership described by Katsaros, it is specified the administrative-bureaucratic role of the director, who consumes much of his creativity in exercising supervision and in particular control. The researcher notes that the exercise of the administrative leadership is highly relevant to the models of leadership applied to many school units in Greece, as the director's initiatives are limited to the stifling context of a law, which imposes on him the role of the executive body of the school administration (Katsaros 2008: 107-108).

The school consultant economists (PE09) Antonis Spanos criticized various models of the exercise of leadership in his article entitled "Methods of administration and leadership of school units", published in the Journal of Scientific Review Educational and scientific issues (Spanos 2014: 40-50).

In particular, in his research, the scholar, reviewing the relevant Greek and foreign literature and after examining the concepts of leadership and administration, for which he determines that they are essential and interrelated, analyses the model of leadership and management based on mutual understanding and cooperation (collegial model) and the one that could transform people working in school units (transformational style). Furthermore, he proposes strategies of motivation that the school director can use in order to achieve a higher concentration of teachers in their work, and the consolidation of a positive school atmosphere.

With regard to the leadership and management model based on mutual understanding and cooperation, Spanos points out that he relied on the assumption that the exercise of power and decision-making within the school unit should be made with the participation of all teachers, who must cooperate with each other. The application of the above model presupposes the observance of democratic principles and procedures. Teachers are supposed to be guided by the same values and beliefs, which helps to avoid obstruction in decision-making.

The above model of exercise of leadership, according to Spanos, is indicated in cases of school units where they serve many teachers, which is very common in the Greek educational system. A vital component of this model is the use of active listening by the director, who does not give orders to teachers but a step to express their views, which he listens carefully. Teachers are, therefore encouraged to take initiatives and promote innovation.

On the contrary, the adoption of the above model impacts on situations where teachers do not manage to agree on general principles, resulting in conflicts. The consensus of all is considered necessary in order to operate the above model of administration, as time is limited in making certain decisions.

Problems can also arise if there is a question of the imputation of responsibilities, if a decision is failed, as in the above-mentioned model of democratic administration the decisions are taken collectively and not exclusively by the Director of the school unit. Obviously, the Director, in this case, cannot "hide" behind the consensus of the Teachers' Association. 
Moreover, a major weakness of the above model, which is related to the character and intentions of each director, is the attempt of some directors to serve their personal interests by manipulating the will of the Teachers' Association.

The administrative and leadership style that could change and transform people working in school units (transformational style) upgrades, according to Spanos, the interest of teachers, contributes to better cooperation between them and matches their objectives with those of the Director of the school unit.

In fact, this pattern of exercise of leadership by the Director and the achievement of predetermined central education objectives by the Ministry of Education within the school unit constitutes the second level of Begley's analysis, which is deviated from the primary purposes of education set by the Ministry (first level) and includes the co-operation of Director-Teachers (third level) and Director of Local Society (fourth level) to achieve common goals.

However, according to Spanos, the adoption of the above leadership style by the school principal undermines the danger of strengthening his powers to the extent that he will become skillful and methodically authoritarian or "despotic" in his behavior towards the educators or will seek to achieve personal aspirations and humble motivations (e.g. professional recognition, self-promotion and awareness).

Moreover, the positive consequences that may result from the exercise of this style of administration may be lost over time, through the centralization that characterizes the education system in Greece, while under conditions it is possible to skewer or ignore the personal capabilities of each teacher in the school unit and his specific character.

Of particular interest in Spano's analysis, using the relevant literature, is his reference to the strategies of motivating the teachers of the school unit that the Director can use in order to get the best of each member of the teachers' team.

It is essential for the Director to personally address each teacher by focusing on his individuality, i.e. his / her character, skills, needs, aspirations. The "levelling" of all the attitudes and the uniform behavior of the Director towards all teachers removes some of the wholes, marginalizes them and contributes to reduced satisfaction.

Moreover, better management of teachers by the school Director may contribute to the practical care of self-improvement and professional development of teachers through various benefits to them. Each teacher's contribution to the work done in the school unit also depends on the degree of freedom and confidence shown by the Director so that the teacher can undertake initiatives that promote innovation.

According to Spanos, the Director must acknowledge the effort and the conscientiousness of the teachers and reward them morally. This finding could add to the observation that the financial benefits of teachers in Greece are slightly lean, and their potential for professional development and social recognition is somewhat limited.

The creation of school culture, the columnist, points out, strengthens the ties of all members 
of the school community, students, teachers and parents. Students are encouraged to apply the school's internal regulations while teachers work together for the school's good in a positive and creative school environment.

In conclusion, the application of both styles of leadership analyzed in the article of Spanos refers to the democratic form of leadership. In my personal opinion, the equal treatment of teachers, their greater or lesser participation in decision-making, recognition of their competences and efforts by the Director are prerequisites for the creation of a favorable climate, as teachers are encouraged to dedicate themselves to the project they are ethically committed to and consistent with the decisions of the Director in serving his vision.

This is shaping the appropriate school culture, which forges relations between the Director and teachers and educators among them, which has an overall impact on the educational process.

However, which of the two proposed models that will be adopted by the Director of the school belongs to his/her discretion? I personally believe that the Director needs to take into account the characters of the teachers as well as the particularities of the school. For example, in a small group of teachers, the model of leadership and administration based on mutual understanding may have been more appropriate.

On the other hand, an essential role in the exercise of leadership is not only the intentions of the teachers but also those of the director himself. The latter, in order to cultivate relationships of trust with professors of the Teachers' Association, should not have "second" thoughts. He needs to be authentic in his behavior, which should not be characterized by hypocrisy and a semblance of democracy.

The real interest of the Director in the needs of teachers, the adoption of the technique of empathy in order to investigate their feelings and motivation of individual professional advancement will form a positive picture for his person to the Teachers' Association, which will have a reflection in relations with his associates.

Because, in this case, the teachers who make up the teachers' club will be real collaborators of the director, not just his subordinates, helping to achieve his vision of shaping creative school culture.

The good communication of the Director with the teachers of the school unit and the good cooperation between the two parties in the decision-making process is facilitated if he cultivates the characteristics of his personality such as creative and critical thinking, teamwork, integrity, discernment, honesty, combined with his experience in the exercise of administrative work and the proper appraisal of existing situations. All of this helps to establish an open communication climate that promotes collaboration and dramatically reduces stress and disappointment in the workplace and especially at school (Papakonstantinou-Anastasiou 2013: 271-272; Chatzipanagiotou 2003: 59-60).

Especially the leadership model the Director adopts influences his intention to gather all the power in himself or to transfer a part of this to his colleagues. If the Director is in favor of the 
administrative and leadership style that could change and transform people working in school units, encourages the participation of the teachers' Association in the decision making process. On the contrary, the authoritarian leadership restricts the participation of the teachers, as it seemed in the case study which is presented below (Papadopoulou 2012: 53-56).

\section{Case Study of Authoritarian Leadership}

A noticeable deviation from the appropriate, in my opinion, the behavior of the director is the case study analyzed below. In particular, at the meeting of a college of teachers in one of the country's high schools, the question of holding a study visit to a nearby area of historical interest was raised.

On the grounds of the teachers who were in favor of the visit and the opinion of which the majority voted in the poll, the necessity of cultivating the historical memory by the students, as provided by the relevant circulars of the Ministry of Education, was put forward.

However, despite the fact that the proposal for the educational visit prevailed at the meeting of the Teachers' Association, the Director dismissed it by citing the bad weather, in his opinion, as well as other "difficulties" of the student's daily program, the reliability of which is controlled.

The teachers of the faculty, newcomers to the majority, who were not from the area where the school was located, were finally "disciplined" in the decision of the director in fear of subsequently displaying hostile and punitive behavior towards them. It is noteworthy that the Director of the school came from the same area and enjoyed the absolute appreciation and trust of the parent and guardians' association.

The Director's action, in this case, can be described as a "coup", a sample of the authoritarian enforcement of the leadership. The Director misconstrued the majority of the Teachers' Association vote, and in effect cancelled a decision of a supreme body in relation to the same administrative body.

The existing legislation in Greece, moreover, states that the Director "must implement the legal decisions of the Teachers 'Association" (article 28 of Ministerial Decision No. 10565/2002). In this respect, therefore, this director has demonstrated not only his authoritarian attitude towards the teachers' association but also his administrative inadequacy and ignorance.

It is evident that the educational visit to the above case study was imposed by the relevant educational legislation and the acceptance of the verdict of the Teachers' Association by the director would be a self-evident act Democratic administration.

On the other hand, the attitude of teachers to "obey" the decision of the director could be characterized as a wise move. Regardless of whether the back of their mind worked the fear of any "sanctions" on the part of the director, they preferred not to disperse the climate in the school unit by creating a "major" issue. Of course, it is not at all certain whether this display of maturity on their part would "excite" the director to change his attitude in the future. 
Perhaps the best option to reconcile the different views of both parties would be to seek the "golden intersection", that is, to find, by the arrangement of both, another date for the realization of the educational visit.

However, the adoption of authoritarian behavior in this case by the director of the school is a "bad advisor" for the school's operation. Moreover, it shows a "proprietary" perception of the school, which does not fit into the profession of an educator. The practical demonstration of "generosity" by the newly appointed teachers could bring him back to the order of the proper Democratic administration.

The above example demonstrates that the school's Director is largely shaping the school climate and is responsible for relations between the members of the school community. The authoritarian director imposes his opinion on the teachers, whom he treats as his subordinates, avoids dialogue and teacher participation in decision making and often invokes the hierarchy in order to legitimize his actions. This attitude poisons the relations of the Director with the teachers, who are governed by formality and coldness.

On the contrary, the Director, who adopts the democratic style of administration, cooperates seamlessly with the teachers' Association, seeks to actively participate in decision-making, resulting to the fact that the teachers of the school unit can communicate intimately with the Director and with each other.

The communication that the Director cultivates, in this case, is authentic, as he does not prioritize his personal interest and the satisfaction of his ambitions but the creation of a school culture with which all members of the school community will be harmonized. The proper functioning of the school presupposes the respect of the personality of each member of the school community; the Director is required to embrace this fundamental principle and not to operate despotically but as first among equals, recognizing his / her colleagues as being able to participate jointly in decision-making.

It worth to note that the level of communication between the Director and the professors is directly related to the degree of emotional intelligence he has achieved. The Director who has acquired a high level of emotional intelligence understands the needs of his colleagues and tries to respond to them according to his possibilities. Of course, improving the functioning of the Teachers' Association is closely related to the emotional intelligence of all of its members and not just the Director's (Goleman 2011: 28).

\section{Conclusions}

In conclusion, we could say that the style chosen by each Director to exercise his leadership has a direct function to its effectiveness, since it affects the critical decisions making and the involvement of the teachers' Association to them.

Research has displayed that the primary behaviours that teachers have experienced by their Director in Greek schools are the "processing" and the "informative". However, teachers do not prefer these two behaviours to be demonstrated by their Director. Nevertheless, they seek a Director who will cooperate with them, educate them, and encourage them to contribute to 
realizing his vision. This fact, may explain several of the deficiencies and weaknesses that arise in the administration of the Greek school (Raptis-Psaras 2015: 211-212).

In any case, however, it is worthwhile to understand that the role of the school Director is particularly crucial for the educational work produced in it and additionally, it is multifarious and multilevel. That is why the Greek state needs to adequately educate not only the active executives but all the teachers, as most of them will be called upon at some point to take managerial positions.

We personally believe that very satisfactory leadership is the one where the Director observes working groups to cooperate and achieve things in common, that they would not be able to accomplish on their own.

\section{References}

Agapitou, Ch. (2012). Teachers' perceptions of professional empowerment: The role of the school director and the influence of leadership style (unpublished. Diploma thesis, University of Thessaly, Department of Primary Education, postgraduate studies programme "Organisation and management of Education").

Andris, E. (2015). Address and leadership. The role of the Director of the school unit, Panhellenic Congress of Education Sciences, (1), 150-155.

Bourantas, D. (2017). Leadership, Athens: Papadopoulos editions.

Chatzipanagiotou, P. (2003). The management of the school and the participation of teachers in the decision-making process, Thessaloniki: Kyriakidi Brothers Publishing House (pedagogy and education, 49).

Goleman, D. (2011). Working with emotional intelligence, Athens: Pedion.

Katsaros, I. (2008). Organization and management of Education, Athens: Pedagogical Institute.

Papadopoulou, O. (2012). Conflicts' management, communication, leadership models and decision making process (unpublished. Diploma thesis, University of Patra, Department of Business Administration, postgraduate studies programme "New rules in the Business Administration".

Papakonstantinou, G., \& Anastasiou, S. (2013). Human resources management principles. The management of the human resources of Education, Athens: Gutenberg.

Raptis, N., \& Psaras, Ch. (2015). Cooperative leadership in Education. The role of the Director and the teachers' Association, Athens: Diadrasi.

Shuttle, H. (2014). Initiation of teachers to the secrets of the school leadership. Modern trends and Practices, Athens: self-publishing.

Spanos, A. (2014). Ways of administration and leadership of school units, Ercya-educational-scientific review, 2, 40-50. 


\section{Copyright Disclaimer}

Copyright for this article is retained by the author(s), with first publication rights granted to the journal.

This is an open-access article distributed under the terms and conditions of the Creative Commons Attribution license (http://creativecommons.org/licenses/by/4.0/). 